\title{
Variações nos teores de nitrogênio mineral em solo suplementado com lodo de esgoto(1)
}

\author{
Rosana Faria Vieira ${ }^{(2)}$ e Antonio Américo Cardoso ${ }^{(3)}$
}

\begin{abstract}
Resumo - O conhecimento da dinâmica da mineralização de materiais orgânicos adicionados ao solo é importante para predizer os efeitos das possíveis perdas de $\mathrm{N}$ para o ambiente. O objetivo deste trabalho foi avaliar a variação do $\mathrm{N}$ mineral, no período da seca e das águas, em solo cultivado com milho, após incorporação de doses crescentes de lodo de esgoto. Os tratamentos constituíram-se de parcelas não fertilizadas, parcelas com adubação nitrogenada (NM), parcelas com dose de lodo de esgoto calculada para fornecer à cultura o mesmo teor de $\mathrm{N}$ do tratamento $\mathrm{NM}(1 \mathrm{~N})$ e parcelas com duas, quatro e oito vezes a dose de lodo de esgoto do tratamento $1 \mathrm{~N}$. As quantidades de lodo de esgoto a serem aplicadas ao solo, devem ser diferentes no período da seca e das águas mesmo quando se baseiam nas necessidades de N, em decorrência das perdas desse elemento em períodos de intensas precipitações.
\end{abstract}

Termos para indexação: Zea mays, mineralização do nitrogênio, imobilização do nitrogênio, biossólido.

\section{Variation on the quantity of mineral nitrogen in a soil amended with sewage sludge}

\begin{abstract}
The knowledge of the organic materials mineralization dynamic added to soil is important to predict the effects of possible $\mathrm{N}$ losses to the environment. The objective of this work was to evaluated the variation of mineral $\mathrm{N}$ in the dry and rainy periods, in a soil cultivated with maize, after its amendement with increasing doses of sewage sludge. The treatments were plots not fertilized, plots with $\mathrm{N}$ fertilization (NM), plots with dose of sewage sludge, calculated to supply the same $\mathrm{N}$ content of the NM treatment $(1 \mathrm{~N})$, and plots with two, four and eight times the sewage sludge dose of the $1 \mathrm{~N}$ treatment. The quantities of biosolid to be added to the soil should be different in the dry and rainy periods, even when they are based on $\mathrm{N}$ of the crop requirement, because great $\mathrm{N}$ losses may occur in periods of high pluvial precipitation.
\end{abstract}

Index terms: Zea mays, nitrogen mineralization, nitrogen immobilization, biosolid.

\section{Introdução}

O lodo de esgoto é um resíduo de composição predominantemente orgânica, obtido ao final do tratamento de águas servidas à população. Com o aumento de sua produção e diante dos problemas ambientais que podem ser causados por seu acúmulo, torna-se cada vez mais urgente a necessidade de utilizá-lo de forma econômica e sem agressões ao

\footnotetext{
(1) Aceito para publicação em 11 de abril de 2003 .

(2) Embrapa-Centro Nacional de Pesquisa de Monitoramento e Avaliação de Impacto Ambiental, Caixa Postal 69, CEP 13820-000 Jaguariúna, SP. E-mail: rosana@cnpma.embrapa.br

(3) Universidade Federal de Viçosa, Dep. de Fitotecnia, Avenida P. H. Rolfs, s/no, CEP 36571-000 Viçosa, MG.

E-mail: aacardoso@ufv.br
}

meio ambiente. Em conseqüência de sua riqueza em nutrientes, principalmente $\mathrm{N}$ e $\mathrm{P}$, a utilização em terras agricultáveis tem apresentado opção racional do uso deste composto orgânico (Oliveira et al., 1995; Vieira, 2001).

No Brasil, embora as pesquisas ainda se encontrem em fase incipiente, diversos trabalhos já demonstraram os benefícios da aplicação do lodo de esgoto no aumento do teor de C orgânico do solo e da CTC (Melo et al.,1994), como fornecedor de nutrientes a diversas culturas (Berton et al., 1989; Oliveira et al., 1995; Biscaia \& Miranda, 1996), no maior retorno econômico em relação ao fertilizante químico (Biscaia \& Miranda, 1996) e na melhoria das propriedades físicas do solo (Jorge et al., 1991).

A composição química do lodo de esgoto depende de sua origem e dos tratamentos de depuração às 
quais ele é submetido. Em geral, os lodos de esgoto são ricos em $\mathrm{N}$, o que significa que possuem alto potencial para serem utilizados como fertilizantes nitrogenados; este $\mathrm{N}$ está presente em várias formas orgânicas e inorgânicas e nem todas são disponíveis para a nutrição da planta. A recomendação da quantidade de lodo de esgoto a ser aplicada é normalmente feita tomando-se como base os teores de N no biossólido (Melo et al., 2001) e os requerimentos da cultura nesse nutriente. É necessário, ainda, o uso de uma fração de mineralização do composto, medida em laboratório, em que a temperatura e os teores de umidade são mantidos sob controle. Considerando que em condições de campo ocorrerão flutuações consideráveis nesses dois fatores climáticos, havendo nos dias de maior precipitação pluvial e nos dias mais quentes um aumento da mineralização do $\mathrm{N}$ orgânico, a aplicação de lodo de esgoto em doses baseadas na sua taxa de mineralização, medida sob condições controladas, poderá superestimar as quantidades a serem aplicadas. A utilização do lodo de esgoto como fonte de $\mathrm{N}$ requer, portanto, um acompanhamento do processo de mineralização deste elemento no solo, uma vez que excessivas quantidades de $\mathrm{NO}_{3}{ }^{-}$poderão, por meio da lixiviação e desnitrificação, respectivamente, contaminar águas subterrâneas ou provocar o desprendimento de óxido nitroso. Burton et al. (1990) encontraram significante nitrificação líquida em solo com aplicações superficiais de lodo de esgoto; seus resultados indicaram lixiviação de nitrato seguida da aplicação do lodo em solos ácidos de floresta. Tais descobertas concordam com prévios estudos conduzidos por Higgins (1984), cuja aplicação de lodo de esgoto na taxa de 44,8 Mg de sólidos secos por ha resultou em forte contaminação das águas subterrâneas.

Este trabalho teve como objetivo avaliar a mineralização e a imobilização do $\mathrm{N}$ em solo cultivado com milho, no período da seca e das águas, após suplementação com doses crescentes de lodo de esgoto.

\section{Material e Métodos}

O experimento foi realizado em um Latossolo Vermelho distroférrico, textura média/argilosa, na Embrapa-Centro Nacional de Pesquisa de Monitoramento e Avaliação de Impacto Ambiental, Jaguariúna, SP, em dois plantios consecutivos de milho. O primeiro plantio foi feito em abril de 1999, no período da seca, e o segundo em dezembro de 1999, no período das águas. Antes do plantio do milho, a área permaneceu sem cultivo por, pelo menos, nove anos e apresentava-se predominantemente com Brachiaria sp.

O experimento foi montado em delineamento de blocos ao acaso, com três repetições e seis tratamentos, num total de 18 parcelas. Os tratamentos consistiram de parcelas sem aplicação de fertilizantes (testemunha), parcelas com aplicação de $\mathrm{N}$ mineral (NM), parcelas com dose de lodo de esgoto calculada para fornecer à cultura o mesmo teor de $\mathrm{N}$ do tratamento $\mathrm{NM}(1 \mathrm{~N})$ e parcelas com duas $(2 \mathrm{~N})$, quatro $(4 \mathrm{~N})$ e oito vezes $(8 \mathrm{~N})$ a dose de lodo do tratamento $1 \mathrm{~N}$. Após ensaios preliminares, para o cálculo das quantidades de lodo de esgoto a serem aplicadas, tomou-se como base uma fração de mineralização do $\mathrm{N}$ orgânico do biossólido de 30\% (Boeira et al., 2002). Baseado nesta estimativa, a quantidade de $\mathrm{N}$ presente no biossólido que seria potencialmente disponível para a cultura foi estimada pela fórmula Ndisp = 30/100 $(\mathrm{Nk}-\mathrm{Nam})+1 / 2 \mathrm{Nam}+\mathrm{Nnit}$ (CETESB, 1999) em que: Ndispé o $\mathrm{N}$ disponível em $\mathrm{kg} \mathrm{kg}^{-1} \mathrm{de}$ lodo; Nk é o N contido no lodo de esgoto (método Kjeldahl); Nam é o teor de $\mathrm{N}$ amoniacal contido no lodo de esgoto; Nnit é o teor de $\mathrm{N}$ nítrico contido no lodo de esgoto. A dose final de lodo, na base seca, foi calculada utilizando-se a fórmula: dose de lodo $\left(\mathrm{kg} \mathrm{ha}^{-1}\right)=\mathrm{N}$ recomendado $\left(\mathrm{kg} \mathrm{ha}^{-1}\right) / \mathrm{N}$ disponível no lodo $\left(\mathrm{kg} \mathrm{kg}^{-1}\right)$. O lodo de esgoto utilizado foi proveniente da estação de tratamento de esgoto de Barueri, SP, que, além de esgotos domésticos, recebe também esgotos industriais. A digestão anaeróbia foi utilizada na estabilização do lodo. Dois lotes diferentes de biossólidos foram utilizados nos dois ensaios e suas características químicas são descritas na Tabela 1. As características químicas do solo medidas antes do primeiro plantio do milho foram: $\mathrm{pH}_{\mathrm{H}_{2} \mathrm{O}} 5,8 ; \mathrm{MO}$, 25,5 $\mathrm{g} \mathrm{dm}^{-3}$; P, 3,5 $\mathrm{mg} \mathrm{dm}^{-3}$ (método da resina); $\mathrm{K}$, $1,51 \mathrm{mmol}_{\mathrm{c}} \mathrm{dm}^{-3} ; \mathrm{Ca}, 27,5 \mathrm{mmol}_{\mathrm{c}} \mathrm{dm}^{-3} ; \mathrm{Mg}, 8,5 \mathrm{mmol}_{\mathrm{c}} \mathrm{dm}^{-3}$; Al, 1,0 $\mathrm{mmol}_{\mathrm{c}} \mathrm{dm}^{-3} ; \mathrm{H}, 35 \mathrm{mmol}_{\mathrm{c}} \mathrm{dm}^{-3}$; CEC, $73,5 \mathrm{mmol}_{\mathrm{c}} \mathrm{dm}^{-3} ; \mathrm{V}, 50,8 \%$.

O lodo de esgoto (8.095, 16.190, 32.381 e $64.762 \mathrm{~kg} \mathrm{ha}^{-1}$, na base seca, no primeiro plantio, e 3.995, 7.991, $15.981 \mathrm{e}$ $31.962 \mathrm{~kg} \mathrm{ha}^{-1}$, na base seca, no segundo plantio) foi aplicado superficialmente nas parcelas e incorporado até $20 \mathrm{~cm}$ de solo, com enxada rotativa, cinco dias antes da semeadura do milho, no período da seca e das águas. As parcelas (20x10 m) incluíram seis linhas de $10 \mathrm{~m}$ com aproximadamente cinco sementes por metro. $\mathrm{O}$ espaçamento entre linhas foi de $0,9 \mathrm{~m}$.

No primeiro cultivo do milho (Zea mays L.) cultivar CATI AL30, as parcelas do tratamento NM foram adubadas com $400 \mathrm{~kg} \mathrm{ha}^{-1}$ da fórmula NPK 4-20-16 no plantio, 
a lanço, e $35 \mathrm{~kg} \mathrm{ha}^{-1} \mathrm{de} \mathrm{N}$ em cobertura, no sulco de plantio, na forma de uréia, aos 40 dias após a emergência (DAE). O cloreto de potássio, na dosagem de $5 \mathrm{~kg} \mathrm{ha}^{-1}$, foi aplicado nas parcelas do tratamento $1 \mathrm{~N}$, a lanço, em decorrência do baixo teor desse elemento no lodo de esgoto utilizado.

No segundo plantio do milho, cultivar AQ 1051, às parcelas do tratamento $\mathrm{NM}$ foram adicionados $450 \mathrm{~kg} \mathrm{ha}^{-1}$ da fórmula NPK 4-20-16 no plantio, a lanço, e $72 \mathrm{~kg} \mathrm{ha}^{-1}$ de N em cobertura, no sulco de plantio, na forma de uréia, aos $40 \mathrm{DAE}$. As parcelas dos tratamentos $1 \mathrm{~N}$, $2 \mathrm{~N}$ e $4 \mathrm{~N}$ receberam ainda, respectivamente, 47,32 e $6 \mathrm{~kg} \mathrm{ha}^{-1}$ de cloreto de potássio, a lanço.

As coletas de amostras de solo para a determinação dos teores de $\mathrm{NH}_{4}{ }^{+}$, do $\mathrm{NO}_{3}{ }^{-}$e dos teores do $\mathrm{N}$ imobilizado foram feitas com a utilização de tubos de PVC, conforme descrito por Raison et al. (1987) e Dou et al. (1997), com algumas modificações. Em cada parcela foram colocados quatro pares de colunas de PVC ( $5 \mathrm{~cm}$ de diâmetro; $22 \mathrm{~cm}$ de altura) distribuídos aleatoriamente nas entrelinhas do milho, à profundidade de $0-20 \mathrm{~cm}$. Dois buracos de $1 \mathrm{~cm}$ foram feitos a $10 \mathrm{~cm}$ do topo da coluna para facilitar a troca de ar e umidade entre o solo externo e interno. Segundo Dou et al. (1997), medições da umidade do solo não mostraram diferenças no conteúdo de água dentro e fora da coluna, confirmando o livre movimento de água neste siste-

Tabela 1. Características químicas dos biossólidos aplicados no primeiro e segundo plantios de milho ${ }^{(1)}$.

\begin{tabular}{lrc}
\hline Parâmetro & $\begin{array}{c}\text { Primeiro } \\
\text { plantio }\end{array}$ & $\begin{array}{c}\text { Segundo } \\
\text { plantio }\end{array}$ \\
\hline $\mathrm{pH}$ & 6,6 & 6,4 \\
$\mathrm{C}$ orgânico $\left(\mathrm{g} \mathrm{kg}^{-1}\right)$ & 248,2 & 271 \\
$\mathrm{~N}($ Kjeldahl $)\left(\mathrm{g} \mathrm{kg}^{-1}\right)$ & 26,0 & 26,4 \\
$\mathrm{~N}$ amoniacal $\left(\mathrm{mg} \mathrm{kg}^{-1}\right)$ & $1.566,9$ & 156 \\
$\mathrm{~N} \mathrm{nítrico}\left(\mathrm{mg} \mathrm{kg}^{-1}\right)$ & 106,2 & 106 \\
$\mathrm{P}\left(\mathrm{resina}^{-1}\left(\mathrm{~g} \mathrm{~kg}^{-1}\right)\right.$ & 15,9 & 31,2 \\
$\mathrm{~K}\left(\mathrm{~g} \mathrm{~kg}^{-1}\right)$ & 1,0 & 1,97 \\
$\mathrm{Ca}\left(\mathrm{g} \mathrm{kg}^{-1}\right)$ & 40,3 & 22,8 \\
$\mathrm{Mg}\left(\mathrm{g} \mathrm{kg}^{-1}\right)$ & 3,0 & 3,7 \\
$\mathrm{Al}\left(\mathrm{mg} \mathrm{kg}^{-1}\right)$ & 28,78 & 25,30 \\
$\mathrm{Cd}\left(\mathrm{mg} \mathrm{kg}^{-1}\right)$ & 12,8 & 9,5 \\
$\mathrm{~Pb}\left(\mathrm{mg} \mathrm{kg}^{-1}\right)$ & 364,4 & 233 \\
$\mathrm{Cu}\left(\mathrm{mg} \mathrm{kg}^{-1}\right)$ & 1.058 & 1.046 \\
$\mathrm{Ni}\left(\mathrm{mg} \mathrm{kg}^{-1}\right)$ & 518,4 & 483 \\
$\mathrm{Zn}\left(\mathrm{mg} \mathrm{kg}^{-1}\right)$ & 2.821 & 3.335 \\
$\mathrm{Fe}\left(\mathrm{mg} \mathrm{kg}^{-1}\right)$ & 54,18 & 32,5 \\
$\mathrm{Bo}\left(\mathrm{mg} \mathrm{kg}^{-1}\right)$ & 36,2 & 11,2 \\
$\mathrm{Mn}\left(\mathrm{mg} \mathrm{kg}^{-1}\right)$ & 429,5 & 335 \\
\hline${ }^{(1)} \mathrm{Os} \mathrm{valores} \mathrm{foram} \mathrm{calculados} \mathrm{com} \mathrm{base} \mathrm{na} \mathrm{matéria} \mathrm{seca} \mathrm{do} \mathrm{lodo} \mathrm{de} \mathrm{esgoto,}$ \\
exceto quanto aos teores de N mineral que foram determinados na amostra \\
original.
\end{tabular}

ma. Nas parcelas do tratamento NM, as colunas foram colocadas o mais próximo possível da linha de aplicação da uréia. Um tubo de cada par foi coberto com tampa de PVC de $10 \mathrm{~cm}$ de diâmetro. A manutenção da metade das colunas no campo, sem tampa, foi uma forma de se procurar entender melhor a mineralização do $\mathrm{N}$, uma vez que, neste caso, permitiu-se que ocorresse o processo de lixiviação do $\mathrm{NO}_{3}{ }^{-}$em períodos de chuva. A quantidade de nitrato lixiviado foi quantificada pela diferença entre os teores desse ânion nos dois sistemas (aberto e fechado). Para a determinação dos teores de $\mathrm{N}$ mineral e do $\mathrm{N}$ da biomassa microbiana, somente foram utilizados os solos provenientes dos tubos abertos. Na determinação do conteúdo inicial do $\mathrm{N}$ mineral e do $\mathrm{N}$ imobilizado foram retiradas amostras de solo no dia em que as colunas foram colocadas no campo pela primeira vez. Os solos contidos nas colunas foram coletados em períodos definidos e novas colunas foram imediatamente recolocadas, em locais escolhidos aleatoriamente, mas nunca a menos de $1 \mathrm{~m}$ das bordaduras. Em cada parcela, as porções do mesmo sistema (aberto e fechado) foram misturadas e homogeneizadas, de modo a se obter três amostras compostas, por tratamento.

No primeiro plantio, as amostragens de solo iniciaramse aos 10 DAE. As primeiras foram realizadas a intervalos de 15 dias e, posteriormente, a intervalos de 21 dias. No segundo plantio, as amostragens iniciaram-se aos 18 DAE e foram repetidas a intervalos de 21 dias. As amostras de solo coletadas no campo foram colocadas em caixas de isopor e levadas ao laboratório, para análise. Para a extração do $\mathrm{NH}_{4}^{+}$e do $\mathrm{NO}_{3}^{-}, 50 \mathrm{~mL}$ de $\mathrm{KCl} 1 \mathrm{~mol} \mathrm{~L}^{-1}$ foram misturados a $5 \mathrm{~g}$ de solo úmido, agitados por $30 \mathrm{mi}-$ nutos a $120 \mathrm{rpm}$ e filtrados. As determinações dos teores de $\mathrm{NH}_{4}{ }^{+} \mathrm{e} \mathrm{NO}_{3}{ }^{-}$nos extratos foram realizadas por destilação a vapor utilizando óxido de magnésio e liga de Devarda (Tedesco et al., 1985).

A técnica de fumigação-extração descrita por Brookes et al. (1985) foi utilizada na determinação do $\mathrm{N}$ da biomassa microbiana do solo no segundo plantio do milho. Resumidamente, $50 \mathrm{~g}$ de solo foram divididos em duas partes. Uma porção foi exposta ao clorofórmio por 24 horas e, posteriormente, misturada a $100 \mathrm{~mL}$ de uma solução $0,5 \mathrm{~mol} \mathrm{~L}^{-1}$ de $\mathrm{K}_{2} \mathrm{SO}_{4}$; a porção não fumigada foi submetida ao mesmo processo de extração, assim que se iniciou a fumigação. Trinta $\mathrm{mL}$ dos extratos foram digeridos e analisados quanto ao $\mathrm{N}$ total (Tedesco et al., 1985). A quantidade de $\mathrm{N}$ na biomassa microbiana foi calculada a partir da fórmula Nmic $=\mathrm{NF}-\mathrm{NNF} / 0,54$, em que NF é o $\mathrm{N}$ total no solo fumigado e $\mathrm{NNF}$ é o $\mathrm{N}$ total no solo não fumigado.

A análise de variância foi realizada determinando-se a probabilidade pelo teste F. Os resultados dos diferentes 
tratamentos de lodo de esgoto foram comparados com a média dos resultados dos tratamentos controle e com adubação química, pelo teste de Dunnett $(\mathrm{P} \leq 0,05)$. Prévia análise não demonstrou diferença significativa entre os tratamentos testemunha e NM. O teste de média foi realizado dentro de cada época de amostragem do solo, tanto no período da seca como das águas.

\section{Resultados e Discussão}

No ensaio realizado no período de seca, as quantidades de $\mathrm{N}$ mineral encontradas no solo aumentaram com as doses de lodo de esgoto aplicadas e foram bem maiores que as obtidas nos tratamentos controle e no tratamento com fertilização nitrogenada, principalmente no início do ciclo da cultura (Tabela 2). Aos $10 \mathrm{DAE}$, os teores de $\mathrm{N}$ mineral nos solos com lodo de esgoto foram, respectivamente, $170 \%$, $306 \%, 557 \%$ e $1.408 \%$ maiores nos tratamentos $1 \mathrm{~N}$,
$2 \mathrm{~N}, 4 \mathrm{~N}$ e $8 \mathrm{~N}$, em relação à média dos tratamentos testemunha e NM. Neste período, a maior parte do N encontrava-se na forma de amônio, em quase todos os tratamentos com lodo de esgoto. A partir de 24 DAE, os teores de $\mathrm{NO}_{3}{ }^{-}$no solo, relativamente aos teores de amônio, começaram a aumentar, indicando intensa nitrificação. Esses resultados indicam que as populações de nitrificadores, além de não serem afetadas pelas doses de lodo de esgoto utilizadas, foram tolerantes às condições de baixa umidade do solo, conforme também verificado por Bramley \& White (1990). Os menores resultados quanto aos teores do $\mathrm{NO}_{3}{ }^{-}$aos $87 \mathrm{DAE}$, em relação aos obtidos aos $66 \mathrm{DAE}$, podem ser conseqüência da ocorrência de lixiviação deste íon para além dos $20 \mathrm{~cm}$ de solo. Naquele período, constatou-se a lixiviação do nitrato de $34,48,73$ e $84 \mathrm{~kg} \mathrm{ha}^{-1}$ da menor para a maior dose de lodo de esgoto (Tabela 3). Embora o experimento tenha sido montado em época de

Tabela 2. Teores de $\mathrm{N}$ mineral em solo cultivado com milho que recebeu diferentes doses de lodo de esgoto (período da seca) ${ }^{(1)}$

\begin{tabular}{|c|c|c|c|c|c|c|c|c|}
\hline \multirow[t]{2}{*}{ Tratamento $^{(2)}$} & \multicolumn{8}{|c|}{ Dias após a emergência } \\
\hline & 10 & 24 & 45 & 66 & 87 & 108 & 129 & 150 \\
\hline & \multicolumn{8}{|c|}{$\mathrm{NH}_{4}{ }^{+}+\mathrm{NO}_{3}{ }^{-}\left(\mu_{\mathrm{g} \mathrm{g}^{-1}}\right)$} \\
\hline Testemunha & 23,67 & 8,67 & 7,00 & 13,00 & 8,00 & 8,67 & 5,33 & 4,33 \\
\hline NM & 19,33 & 5,33 & 4,67 & 10,33 & 9,33 & 11,67 & 5,33 & 4,34 \\
\hline $1 \mathrm{~N}$ & $58,00 \mathrm{a}$ & $21,00 \mathrm{a}$ & $39,33 a$ & $26,33 \mathrm{a}$ & 15,00 & 13,00 & 11,00 & $22,67 \mathrm{a}$ \\
\hline $2 \mathrm{~N}$ & $87,33 a$ & $44,00 \mathrm{a}$ & $53,67 \mathrm{a}$ & $58,67 \mathrm{a}$ & $34,33 \mathrm{a}$ & $33,00 \mathrm{a}$ & $21,67 \mathrm{a}$ & $16,42 \mathrm{a}$ \\
\hline $4 \mathrm{~N}$ & $141,33 \mathrm{a}$ & $81,67 \mathrm{a}$ & $99,33 a$ & $112,00 \mathrm{a}$ & $67,33 \mathrm{a}$ & $69,00 \mathrm{a}$ & $75,00 \mathrm{a}$ & $104,67 \mathrm{a}$ \\
\hline \multirow[t]{2}{*}{$8 \mathrm{~N}$} & $324.33 \mathrm{a}$ & $133.00 \mathrm{a}$ & $179.67 \mathrm{a}$ & $213.67 \mathrm{a}$ & $99.00 \mathrm{a}$ & $170.67 \mathrm{a}$ & $203.33 a$ & $204,35 \mathrm{a}$ \\
\hline & \multicolumn{8}{|c|}{$\mathrm{NH}_{4}^{+}\left(\mu \mathrm{g} \mathrm{g}^{-1}\right)$} \\
\hline Testemunha & 6,34 & 2,67 & 2,00 & 3,33 & 4,67 & 4,00 & 2,00 & 2,33 \\
\hline NM & 5,67 & 1,67 & 1,67 & 4,33 & 4,67 & 4,33 & 2,33 & 1,67 \\
\hline $1 \mathrm{~N}$ & $28,33 a$ & 7,67 & 6,33 & 7,00 & 6,67 & 6,00 & 3,33 & 8,00 \\
\hline $2 \mathrm{~N}$ & $62,00 \mathrm{a}$ & $20,00 \mathrm{a}$ & $11,00 \mathrm{a}$ & 14,33 & 7,33 & 8,67 & 4,67 & 5,67 \\
\hline $4 \mathrm{~N}$ & $110,67 \mathrm{a}$ & $41,33 a$ & $29,00 \mathrm{a}$ & $22,33 a$ & $16,67 \mathrm{a}$ & $12,33 \mathrm{a}$ & $12,67 \mathrm{a}$ & $16,33 \mathrm{a}$ \\
\hline \multirow[t]{2}{*}{$8 \mathrm{~N}$} & $283,33 \mathrm{a}$ & $67,33 \mathrm{a}$ & $63,00 \mathrm{a}$ & $70,33 a$ & $30,00 \mathrm{a}$ & $21,67 \mathrm{a}$ & $34,67 \mathrm{a}$ & $48,67 \mathrm{a}$ \\
\hline & \multicolumn{8}{|c|}{$\mathrm{NO}_{3}^{-}\left(\mu \mathrm{g} \mathrm{g}^{-1}\right)$} \\
\hline Testemunha & 17,33 & 6,00 & 5,00 & 9,67 & 3,33 & 4,67 & 3,33 & 2,00 \\
\hline NM & 13,67 & 3,67 & 3,00 & 6,00 & 4,67 & 7,33 & 3,00 & 2,67 \\
\hline $1 \mathrm{~N}$ & $29,67 \mathrm{a}$ & $13,33 \mathrm{a}$ & $33,00 \mathrm{a}$ & $19,33 a$ & 8,33 & 7,00 & 7,67 & $14,67 \mathrm{a}$ \\
\hline $2 \mathrm{~N}$ & $25,33 a$ & $24,00 \mathrm{a}$ & $42,67 \mathrm{a}$ & $44,33 \mathrm{a}$ & $27,00 \mathrm{a}$ & $24,33 \mathrm{a}$ & $17,00 \mathrm{a}$ & $14,33 \mathrm{a}$ \\
\hline $4 N$ & $30,67 a$ & $40,33 a$ & $70,33 a$ & $89,67 \mathrm{a}$ & $50,67 \mathrm{a}$ & $56,67 \mathrm{a}$ & $62,33 a$ & $88,33 \mathrm{a}$ \\
\hline $8 \mathrm{~N}$ & $41,00 \mathrm{a}$ & $65,67 \mathrm{a}$ & $116,67 \mathrm{a}$ & $143,33 \mathrm{a}$ & $69,00 \mathrm{a}$ & $149,00 \mathrm{a}$ & $168,67 \mathrm{a}$ & $155,67 \mathrm{a}$ \\
\hline
\end{tabular}

(1)Médias seguidas pela letra a, em cada época de avaliação, diferem significativamente da média entre os tratamentos testemunha e NM pelo teste de Dunnett a $5 \%$ de probabilidade. ${ }^{(2)} \mathrm{NM}$ : tratamento que recebeu fertilização nitrogenada; $1 \mathrm{~N}$ : tratamento com lodo de esgoto em dose calculada para fornecer à cultura o mesmo teor de $\mathrm{N}$ do tratamento $\mathrm{NM} ; 2 \mathrm{~N}, 4 \mathrm{~N}$ e $8 \mathrm{~N}$ : tratamentos com lodo de esgoto que receberam duas, quatro e oito vezes, respectivamente, a quantidade de lodo de esgoto do tratamento $1 \mathrm{~N}$ 
seca, alguns períodos de precipitação moderada antecederam a amostragem. Estas altas concentrações de nitrato demonstram o grande potencial para lixiviação do nitrato em solos suplementados com lodo de esgoto.

As maiores perdas de $\mathrm{N}$ nos tratamentos com lodo de esgoto devem ocorrer no início do ciclo da cultura, quando a exigência da planta por esse elemento ainda é pequena. A quantidade recomendada de fertilizante nitrogenado aplicado no plantio, ou seja, $20 \mathrm{~kg} \mathrm{ha}^{-1}$ de $\mathrm{N}$, foi bem menor que os $116 \mathrm{~kg} \mathrm{ha}^{-1} \mathrm{de}$ $\mathrm{N}$ encontrados aos 10 DAE, no tratamento 1N. É importante salientar que este valor não considerou as perdas de $\mathrm{N}$ por lixiviação antes desta primeira amostragem.

No período das águas, as quantidades de $\mathrm{N}$ mineral encontradas foram bem menores que as obtidas no período da seca (Tabela 4), independentemente da quantidade de lodo de esgoto aplicada, apesar da maior umidade do solo e das maiores temperaturas, fatores estes que aceleram a mineralização (Terry et al., 1981). Poucas diferenças significativas foram encontradas entre os teores de amônio e nitrato nos solos suplementados com lodo de esgoto, em relação à média dos tratamentos testemunha e NM. Aos 60 DAE, observou-se um decréscimo nos teores de $\mathrm{N}$ mineral em todos os tratamentos, o que pode estar relacionado a um prolongado período de seca ocorrido próximo desta avaliação. O somatório dos teores de nitrato lixiviados foram também menores que os verificados no período da seca (Tabela 5).

$\mathrm{O}$ decréscimo na quantidade de $\mathrm{N}$ mineral encontrado na época das águas poderia estar relacionado a um efeito tóxico do lodo de esgoto, quando aplica- do de forma seqüenciada, sobre os microrganismos do solo. Dessa maneira, a adição do biossólido poderia provocar um acúmulo de substâncias orgânicas tóxicas à microflora, prejudicando a mineralização. Wiseman \& Zibilske (1988), porém, contrariamente a tal suposição, demonstraram que a taxa inicial de mineralização do $\mathrm{N}$ orgânico, em solo suplementado com lodo de esgoto que já havia previamente recebido o biossólido, foi maior em decorrência da aclimatação da microflora do solo ao substrato. Lindermann et al. (1988) não observaram efeitos da prévia suplementação do solo com lodo na mineralização do biossólido recentemente aplicado. Gilmour et al. (1996) não obtiveram evidências que sugerissem que o biossólido residual afetasse a taxa ou a extensão da decomposição do biossólido aplicado posteriormente. A menor quantidade de $\mathrm{N}$ mineral, no período das águas, portanto, pode estar associada à maior perda deste elemento no início do ciclo vegetativo do milho. Nos primeiros 20 dias após a aplicação do biossólido ocorreram intensos períodos de chuvas, que prejudicaram algumas vezes a drenagem do solo. Em consequiência, perdas de $\mathrm{N}$ na forma de $\mathrm{NO}_{3}{ }^{-}$, por lixiviação ou mesmo por desnitrificação, podem ter ocorrido de forma intensa. Por não terem sido medidos os teores de nitrato a profundidades maiores, esta questão permanece em aberto. Os resultados da Tabela 4, porém, mostram que, conforme ocorrido no período da seca, a nitrificação foi intensa nos solos suplementados com lodo de esgoto. Neste segundo plantio deve-se, também, levar em consideração que, em decorrência das intensas chuvas que ocorreram após a aplicação do lodo de esgoto, o método utilizado para medir a

Tabela 3. Teores de nitrato lixiviados dos primeiros $20 \mathrm{~cm}$ de solo cultivado com milho que recebeu diferentes doses de lodo de esgoto (período da seca).

\begin{tabular}{|c|c|c|c|c|c|c|c|c|c|}
\hline \multirow[t]{2}{*}{ Tratamento $^{(1)}$} & \multicolumn{9}{|c|}{ Dias após a emergência } \\
\hline & 10 & 24 & 45 & 66 & 87 & 108 & 129 & 150 & Total \\
\hline & \multicolumn{9}{|c|}{$\mathrm{NO}_{3}^{-}\left(\mu \mathrm{g} \mathrm{g}^{-1}\right)$} \\
\hline Testemunha & $-(2)$ & 14,67 & 5,67 & 1,33 & 8,00 & - & 2,34 & 3,00 & 35,01 \\
\hline NM & - & 9,33 & 5,33 & 1,00 & 1,33 & - & - & 1,66 & 18,65 \\
\hline $1 \mathrm{~N}$ & - & 17,00 & 10,67 & - & 17,00 & 5,33 & 1,66 & - & 51,66 \\
\hline $2 \mathrm{~N}$ & - & 7,33 & 17,00 & - & 24,00 & - & 4,67 & 10,92 & 63,92 \\
\hline $4 \mathrm{~N}$ & - & 2,34 & 26,34 & 5,67 & 36,72 & 10,00 & - & - & 81,07 \\
\hline $8 \mathrm{~N}$ & - & 22,66 & 44,00 & 5,00 & 42,00 & - & 39,34 & 34,66 & 187,60 \\
\hline
\end{tabular}

(1) NM: tratamento que recebeu fertilização nitrogenada; $1 \mathrm{~N}$ : tratamento com lodo de esgoto em dose calculada para fornecer à cultura o mesmo teor de $\mathrm{N}$ do tratamento $\mathrm{NM} ; 2 \mathrm{~N}, 4 \mathrm{~N}$ e $8 \mathrm{~N}$ : tratamentos com lodo de esgoto que receberam duas, quatro e oito vezes, respectivamente, a quantidade de lodo de esgoto do tratamento $1 \mathrm{~N}$. ${ }^{(2)}$ Lixiviação não detectada. 
lixiviação do nitrato para além dos primeiros $20 \mathrm{~cm}$ do solo pode não ter sido eficiente; grandes quantidades de $\mathrm{NO}_{3}{ }^{-}$podem ter sido lixiviados mesmo dos tubos fechados.

Os dados relativos aos teores de $\mathrm{N}$ na biomassa microbiana do solo descartam a possibilidade de que grandes quantidades de $\mathrm{N}$ tenham sido imobilizadas pela microbiota do solo. À exceção da primeira coleta, em que os teores de $\mathrm{N}$ na biomassa microbiana foram maiores com a aplicação do lodo de esgoto (Tabela 6), não houve diferenças significativas entre os tratamentos em relação a este parâmetro $(\mathrm{P}<0,05$, teste $\mathrm{F})$.

Tabela 4. Teores de $\mathrm{N}$ mineral em solo cultivado com milho que recebeu diferentes doses de lodo de esgoto (período das águas) $)^{(1)}$.

\begin{tabular}{|c|c|c|c|c|c|c|c|}
\hline \multirow[t]{2}{*}{ Tratamento $^{(2)}$} & \multicolumn{7}{|c|}{ Dias após a emergência } \\
\hline & 18 & $39^{(3)}$ & 60 & 81 & 102 & 123 & 144 \\
\hline & \multicolumn{7}{|c|}{$\mathrm{NH}_{4}{ }^{+}+\mathrm{NO}_{3}^{-}\left(\mu \mathrm{g} \mathrm{g}^{-1}\right)$} \\
\hline Testemunha & 6,17 & - & 4,34 & 10,34 & 7,00 & 5,34 & 6,00 \\
\hline NM & 5,62 & - & 4,33 & 14,00 & 8,01 & 8,01 & 5,34 \\
\hline $1 \mathrm{~N}$ & 3,97 & - & 2,67 & 12,00 & 8,34 & 7,01 & 7,01 \\
\hline $2 \mathrm{~N}$ & 13,21 & - & 2,34 & 17,34 & 8,34 & 14,34 & $14,00 \mathrm{a}$ \\
\hline $4 \mathrm{~N}$ & $24,38 \mathrm{a}$ & - & 5,67 & 20,00 & 12,34 & $18,67 \mathrm{a}$ & $15,67 \mathrm{a}$ \\
\hline $8 \mathrm{~N}$ & $47.36 \mathrm{a}$ & - & 9.01 & $41.34 \mathrm{a}$ & 15.67 & $30.00 \mathrm{a}$ & $35,34 \mathrm{a}$ \\
\hline & \multicolumn{7}{|c|}{$\mathrm{NH}_{4}^{+}\left(\mu \mathrm{g} \mathrm{g}^{-1}\right)$} \\
\hline Testemunha & 3,62 & - & 1,00 & 5,67 & 3,00 & 2,00 & 2,00 \\
\hline NM & 3,36 & - & 1,33 & 4,00 & 3,67 & 2,67 & 1,00 \\
\hline $1 \mathrm{~N}$ & 1,69 & - & 1,33 & 4,67 & 3,67 & 1,67 & 2,67 \\
\hline $2 \mathrm{~N}$ & 3,55 & - & 1,00 & $9,34 \mathrm{a}$ & 3,00 & 3,34 & 3,00 \\
\hline $4 N$ & $9,34 \mathrm{a}$ & - & 1,33 & 4,00 & 3,34 & 2,00 & 2,00 \\
\hline $8 \mathrm{~N}$ & $11,33 \mathrm{a}$ & - & 2.34 & 6,67 & 4,33 & 2,34 & 3,67 \\
\hline \multicolumn{8}{|c|}{$\mathrm{NO}_{3}^{-}\left(\mu \mathrm{g} \mathrm{g}^{-1}\right)$} \\
\hline Testemunha & 2,56 & - & 3,34 & 4,67 & 4,00 & 3,34 & 4,00 \\
\hline NM & 2,26 & - & 3,00 & 10,00 & 4,34 & 5,34 & 4,34 \\
\hline $1 \mathrm{~N}$ & 2,28 & - & 1,34 & 7,33 & 4,67 & 5,34 & 4,34 \\
\hline $2 \mathrm{~N}$ & 9,65 & - & 1,34 & 8,00 & 5,34 & 11,00 & $11,00 \mathrm{a}$ \\
\hline $4 N$ & $15,04 \mathrm{a}$ & - & 4,34 & 16,00 & 9,00 & $16,67 \mathrm{a}$ & $13,67 \mathrm{a}$ \\
\hline $8 \mathrm{~N}$ & $36,03 \mathrm{a}$ & - & 6,67 & $34,67 \mathrm{a}$ & $11,34 \mathrm{a}$ & $20,34 \mathrm{a}$ & $31,67 \mathrm{a}$ \\
\hline
\end{tabular}

${ }^{(1)}$ Médias seguidas pela letra a, em cada época de avaliação, diferem significativamente da média entre os tratamentos testemunha e NM pelo teste de Dunnett a $5 \%$ de probabilidade. ${ }^{(2)} \mathrm{NM}$ : tratamento que recebeu fertilização nitrogenada; $1 \mathrm{~N}$ : tratamento com lodo de esgoto em dose calculada para fornecer à cultura o mesmo teor de $\mathrm{N}$ do tratamento $\mathrm{NM} ; 2 \mathrm{~N}, 4 \mathrm{~N}$ e $8 \mathrm{~N}$ : tratamentos com lodo de esgoto que receberam duas, quatro e oito vezes, respectivamente, a quantidade de lodo de esgoto do tratamento $1 \mathrm{~N} .{ }^{(3)}$ Aos 39 DAE os dados não foram coletados.

Tabela 5. Teores de nitrato lixiviados dos primeiros $20 \mathrm{~cm}$ do solo cultivado com milho, que recebeu diferentes doses de lodo de esgoto (período das águas).

\begin{tabular}{|c|c|c|c|c|c|c|c|c|}
\hline \multirow[t]{2}{*}{ Tratamento $^{(1)}$} & \multicolumn{8}{|c|}{ Dias após a emergência } \\
\hline & 18 & 39 & 60 & 81 & 102 & 123 & 144 & Total \\
\hline & \multicolumn{8}{|c|}{$\mathrm{NO}_{3}^{-}\left(\mu \mathrm{g} \mathrm{g}^{-1}\right)$} \\
\hline Testemunha & $-(2)$ & 2,50 & 4,33 & - & - & 1,00 & 0,34 & 8,17 \\
\hline NM & - & - & 36,00 & 4,00 & 0,66 & - & 3,00 & 43,66 \\
\hline $1 \mathrm{~N}$ & - & 2,83 & 11,33 & - & 0,33 & 1,00 & 2,66 & 18,15 \\
\hline $2 \mathrm{~N}$ & - & 1,00 & 16,66 & - & 0,64 & - & 4,34 & 22,64 \\
\hline $4 \mathrm{~N}$ & - & 15,33 & 24,99 & 4,00 & 12,33 & - & 3,33 & 59,98 \\
\hline $8 \mathrm{~N}$ & - & 34,67 & 47,33 & 4,33 & 17,99 & - & - & 104,32 \\
\hline
\end{tabular}


Tabela 6. Nitrogênio da biomassa microbiana ( $\mu \mathrm{g} \mathrm{g}^{-1}$ de solo) em solo cultivado com milho que recebeu diferentes doses de lodo de esgoto (período das águas).

\begin{tabular}{cccccccr}
\hline Tratamento $^{(1)}$ & \multicolumn{7}{c}{ Dias após a emergência } \\
\cline { 2 - 8 } & 18 & $39^{(2)}$ & 60 & 81 & 102 & 123 & 144 \\
\hline Testemunha & 10,01 & - & 24,89 & 19,41 & 32,01 & 19,24 & 7,83 \\
NM & 14,05 & - & 24,12 & 19,09 & 31,61 & 24,62 & 11,07 \\
1N & 22,37 & - & 26,27 & 22,30 & 41,70 & 25,24 & 13,79 \\
2N & 28,59 & - & 26,36 & 24,91 & 32,34 & 22,47 & 10,60 \\
4N & 26,11 & - & 24,12 & 26,81 & 31,54 & 17,10 & 8,74 \\
$8 \mathrm{~N}$ & 31,40 & - & 26,73 & 28,72 & 36,36 & 21,59 & 13,75 \\
\hline
\end{tabular}

(1) NM: tratamento que recebeu fertilização nitrogenada; $1 \mathrm{~N}$ : tratamento com lodo de esgoto em dose calculada para fornecer à cultura o mesmo teor de $\mathrm{N}$ do tratamento NM; $2 \mathrm{~N}, 4 \mathrm{~N}$ e $8 \mathrm{~N}$ : tratamentos com lodo de esgoto que receberam duas, quatro e oito vezes, respectivamente, a quantidade de lodo de esgoto do tratamento $1 \mathrm{~N} .{ }^{(2)}$ Aos 39 DAE os dados não foram coletados

A aplicação de doses de lodo de esgoto baseadas no requerimento da cultura em $\mathrm{N}$ requer a utilização de uma fração de mineralização do biossólido para calcular o N que estará disponível para a planta (Melo et al., 2001). Esta taxa é, contudo, obtida por meio da incubação do lodo de esgoto em condições controladas de laboratório e pode, portanto, não ser uma estimativa acurada da mineralização sob condições de campo. As tabelas com os resultados relativos aos teores de $\mathrm{N}$ mineral nos dois ensaios demonstram não haver tendência lógica na mineralização do N, uma vez que, em condições de campo, ela está sujeita a diferentes interferências climáticas. Deve-se também considerar que as quantidades de $\mathrm{N}$ exigidas pelas culturas e fornecidas pelos fertilizantes são aplicadas de forma parcelada e em períodos de maior demanda da cultura, evitandose que ocorram perdas para o ambiente. Tal fato não é levado em consideração quando se utiliza o lodo de esgoto, o que poderá ocasionar grandes perdas de $\mathrm{N}$ principalmente no início do cultivo de diferentes plantas. Este fato torna-se mais crítico em cultivos realizados em períodos de chuvas; alta umidade além de aumentar a lixiviação do nitrato cria microssítios anaeróbios que, associados à presença de $\mathrm{C}$ orgânico do lodo de esgoto, podem aumentar as perdas de $\mathrm{NO}_{3}{ }^{-}$pela desnitrificação.

A grande diferença observada nos teores de $\mathrm{N}$ mineral no solo, entre os cultivos realizados no período da seca e no período chuvoso, ao longo de todo o cultivo do milho, demonstra que a época de plantio de determinada cultura deveria também ser levada em consideração no cálculo das quantidades de lodo de esgoto a serem aplicadas.

\section{Conclusão}

A recomendação de doses de lodo de esgoto baseada no requerimento de $\mathrm{N}$ pela cultura e na fração de mineralização do biossólido pode ocasionar perdas de $\mathrm{N}$ do ecossistema solo, principalmente no início do ciclo vegetativo da cultura, com conseqüências danosas para o ambiente.

\section{Referências}

BERTON, R. S.; CAMARGO, O. A.; VALADARES, J. M. A. S. Absorção de nutrientes pelo milho em resposta à adição de lodo de esgoto a cinco solos paulistas. Revista Brasileira de Ciência do Solo, Campinas, v. 13, p. 187-192, 1989.

BISCAIA, R. C. M.; MIRANDA, G. M. Uso de lodo de esgoto calado na produção do milho. Sanare, Curitiba, v. 5, p. 90-92, 1996.

BOEIRA, R. C.; LIGO, M. A. V.; DYNIA, J. F. Mineralização de nitrogênio em solo tropical tratado com lodos de esgoto. Pesquisa Agropecuária Brasileira, Brasília, v. 37, n. 11, p. 1639-1647, nov. 2002.

BRAMLEY, R. G. V.; WHITE, R. E. The variability of nitrifying activity in field soils. Plant and Soil, Dordrecht, v. 126, p. 203-208, 1990.

BROOKES, P. C.; LANDMAN, A.; PRUDEN, G.; JENKINSON, D. S. Chloroform fumigation and the release of soil nitrogen: a rapid direct extraction method to measure microbial biomass nitrogen in soil. Soil Biology Biochemistry, Oxford, v. 17, p. 837-842, 1985.

BURTON, J. A.; HART JUNIOR, J. B.; URIE, D. H. Nitrification in sludge-amended Michigan forest soils. 
Journal of Environmental Quality, Madison, v. 19, p. 600-616, 1990.

CETESB. Sistemas de aplicação de biossólidos e lodos de tratamentos biológicos em áreas de uso agrícola critérios para projetos e operação. São Paulo, 1999, 29 p. (CETESB, Norma P4230).

DOU, H.; ALVA, A. K.; KHAKURAL, B. R. Nitrogen mineralization from citrus tree residues under different production conditions. Soil Science Society of America Journal, Madison, v. 61, p. 1226-1232, 1997.

GILMOUR, J. T.; ROMAN, F.; CLARK, M. D. Decomposition of biosolids in a disposal site soil.Journal of Environmental Quality, Madison, v. 25, p. 1083-1086, 1996.

HIGGINS, J. A. Land application of sewage sludge with regard to cropping system and pollution potential. Journal of Environmental Quality, Madison, v. 13, p. 441-448, 1984.

JORGE, J. A.; CAMARGO, O. A.; VALADARES, J. M. A. S. Condições físicas de um Latossolo VermelhoEscuro quatro anos após aplicação de lodo de esgoto e calcário. Revista Brasileira de Ciência do Solo, Campinas, v. 15, p. 237-240, 1991.

LINDERMANN, W. C.; CONNELL, G.; URQUHART, N. S. Previous sludge addition effects on nitrogen mineralization in freshly amended soil. Soil Science Society of America Journal, Madison, v. 52, p. 109 $112,1988$.

MELO, W. J.; MARQUES, M. O.; MELO, V. P. O uso agrícola do biossólido e as propriedades do solo. In: TSUTIYA, M. T.; COMPARINI, J. B.; ALEM SOBRINHO, P.; HESPANHOL, I.; CARVALHO, P. C. T.;
MELFI, A. J.; MELO, W. J.; MARQUES, M. O. (Ed.). Biossólidos na agricultura. São Paulo: Companhia de Saneamento Básico do Estado de São Paulo, 2001. p. 289363.

MELO, W. J.; MARQUES, M. O.; SANTIAGO, G.; CHELLI, R. A.; LEITE, S. A. S. Efeito de doses crescentes de lodo de esgoto sobre frações da matéria orgânica e CTC de um latossolo cultivado com cana-de-açúcar. Revista Brasileira de Ciência do Solo, Campinas, v. 18, p. 449-455, 1994.

OLIVEIRA, F. C.; MARQUES, M. O.; BELLINGIERI, P. A.; PERECIN, D. Lodo de esgoto como fonte de macronutrientes para a cultura do sorgo granífero. Scientia Agricola, Piracicaba, v. 52, p. 360-367, 1995.

RAISON, R. J.; CONNELE, M. J.; KHANNA, P. K. Methodology for studying fluxes of soil mineral $\mathrm{N}$ in situ. Soil Biology \& Biochemistry, Oxford, v. 19, p. 521-530, 1987.

TEDESCO, M. J.; VOLKWEISS, S. J.; BOHNEN, H. Análise de solo, plantas e outros materiais. Porto Alegre: UFRGS, 1985. p. 2.54-2.64. (Boletim Técnico, 5).

TERRY, R. E.; NELSON, D. W.; SOMMERS, L. E. Nitrogen transformations in sewage sludge-amended soils as affected by soil environmental factors. Soil Science Society of America Journal, Madison, v. 45, p. 506$512,1981$.

VIEIRA, R. F. Sewage sludge effects on soybean growth and nitrogen fixation. Biology and Fertility of Soils, Berlin, v. 34, p. 196-200, 2001.

WISEMAN, J. T.; ZIBILSKE, L. M. Effects of sludge application sequence on carbon and nitrogen mineralization in soil. Journal Environmental Quality, Madison, v. 17, p. 334-339, 1988. 